\title{
RESONANT PROCESSES IN STARTING MODES OF SYNCHRONOUS MOTORS WITH CAPACITORS IN THE EXCITATION WINDINGS CIRCUIT
}

Purpose. Development of a mathematical model that enables to detect resonance modes during asynchronous startup of salientpole synchronous motors, in which capacitors are switched on to increase the electromagnetic moment in the circuit of the excitation winding. Methodology. The asynchronous mode is described by a system of differential equations of the electric equilibrium of motor circuits written in orthogonal coordinate axes. The basis of the developed algorithm is the mathematical model of the high-level adequacy motor and the projection method for solving the boundary value problem for the equations of the electric equilibrium of the circuits written in orthogonal coordinate axes, taking into account the presence of capacitors in the excitation winding. The coefficients of differential equations are the differential inductances of the motor circuits, which are determined on the basis of the calculation of its magnetic circuit. As a result of the asymmetry of the rotor windings in the asynchronous mode, the current coupling and currents change according to the periodic law. The problem of its definition is solved as a boundary one. Results. A mathematical model for studying the asynchronous characteristics of synchronous motors with capacitors in an excitation winding is developed, by means of which it is possible to investigate the influence of the size of the capacity on the motor's starting properties and the resonance processes which may arise in this case. Scientific novelty. The developed method of mathematical modeling is based on a fundamentally new mathematical basis for the calculation of stationary dynamic modes of nonlinear electromagnetic circuits, which enables to obtain periodic coordinate dependencies, without resorting to the calculation of the transients. The basis of the developed algorithm is based on the approximation of state variables by cubic splines, the projection method of decomposition for the boundary value problems of the calculation of the established periodic modes and the differential method of calculating static characteristics. Practical value. Using the developed algorithm of calculation it is possible to determine the required capacitances of the capacitors in the excitation winding to start the synchronous motor and to investigate the possibility of occurrence of the resonance at startup with the selected capacitance value of the capacitors by calculating the static characteristics as a sequence of asynchronous modes. References 8, figures 2 . Key words: salient-pole synchronous motor, capacitors, excitation winding, resonance, static characteristics.

Рассматривается проблема возникновения резонанса во время асинхронного пуска явнополюсных синхронных двигателей, в которых для повышения электромагнитного момента в цепь обмотки возбуждения включены конденсаторы. Для расчета пусковых статических характеристик и исследования влияния величинь емкости конденсаторов на протекание пуска двигателя, в частности появления резонанса, используется математическая модель синхронного двигателя явнополюсной конструкции высокого уровня адекватности, в которой учитывается насыщение магнитопровода. Асинхронный режим описывается системой дифференциальных уравнений электрического равновесия, составленной в ортогональных координатных осях с учетом наличия конденсаторов в обмотке возбуждения. Электромагнитные параметры контуров определяются путем расчета разветвленной схемы замещения магнитной цепи двигателя. В основу разработанного алгоритма положен основанный на аппроксимации кубическими сплайнами проекционный метод решения краевых задач расчета установившихся периодических режимов и дифференциальный метод расчета статических характеристик. Библ. 8, рис. 2.

Ключевые слова: явнополюсний синхронный двигатель, конденсаторы, обмотка возбуждения, резонанс, статические характеристики.

Introduction. Despite the higher cost and complexity comparing with induction motors in manufacturing, synchronous motors are used in electric drives of high power, especially where low rotation speeds are required. The problem of starting synchronous motors, which operate in powerful electric drives, is one of the main. Its essence is to provide the necessary starting torque, which is conditioned by the operating conditions of the drive. They are made primarily with salient poles, which have an excitation winding. To access the synchronous mode, the rotor of the motor must be accelerated to close to the synchronous speed of rotation, after which to apply to the winding excitation DC, the rotor will become an electromagnet and will enter into synchronism.

Among the known methods of starting, most often used asynchronous start, as simple and reliable, which is carried out through direct switching to a network with a nominal voltage. For asynchronous start-up, copper or brass rods are inserted into each pole of a salient-pole synchronous motor (SSM), which are connected from the ends with short-circuiting rings. As a result, we obtain a starting winding, which is analogous to the short-circuit winding of the rotor of the induction motor, and allows to accelerate the motor to a sub-synchronous speed. This winding simultaneously acts as a damper and eliminates random oscillations. Since there are no rods in the interpolar gap, it is asymmetric, as a result of which the distribution of magnetic flux density in the air gap differs from the sinusoidal one, and the electromagnetic torque in the stable asynchronous mode has constant and variable components. In addition, the saturation of the magnetic circuit affects the processes in the SSM.

During the induction start the excitation winding is usually short-circuit on resistive resistance value of 
5-10 $\Omega$, and it almost does not participate in the creation of electromagnetic torque. Nevertheless, in case of starting of SSM under load the electromagnetic torque which is created by starting winding of the rotor in asynchronous mode, is insufficient for the successful startup, so they use various means to improve it. One of the ways to solve the problem is to use the excitation winding. However, it has a large inductance, and therefore alternating current that takes place in it in the starting mode is inductive and can not create significant additional torque. To compensate inductive reactance of the excitation winding is possible by sequentially switching capacitors [6, 7], but SSM start with capacitors in the excitation winding requires thorough research as an unfortunate choice of their capacitance values can lower starting electromagnetic torque [2, 5]. Also, having capacitors in excitation winding can cause effects of voltages resonance, which is dangerous for winding and for the motor as a whole due to resonance caused unacceptably high currents and electromagnetic torque. So the problem of the study of the processes that arise in synchronous electric drives in the case of the connection of capacitors in the winding of excitation is of great practical importance.

The method of increasing the starting electromagnetic torque by means of connection in the excitation winding of the SSM capacitors known in the literature for a long time, but the problem of mathematical modeling of processes, which accompany their asynchronous start, remains unresolved so far. This is mainly due to the fact that the study of processes occurring under such a start-up method was carried out on simplified mathematical models based on the classical equivalent circuits of the motor $[6,7]$, which a priori requires experimental verification. However, experiments on high-power SSM are too expensive, and some of them can not be implemented for technical reasons. Clarification of the calculations on the basis of the use of chain multi-circuit equivalent circuits [1] is not universal, since it is tied to a specific electric drive, and therefore does not solve the problem of the adequacy of the calculation results. Therefore, the methods of analysis, which are based on both the classical and advanced equivalent circuits of the IM, do not provide the reliability of the parameters in the dynamic modes, and the errors in the parameters can lead to incorrect results.

As is known, the condition of resonance is determined by the parameters of the electric circuit, in particular, the excitation winding, which does not work isolated, but in the system of complex electromagnetic connections with other circuits of the motor, which carry out reciprocal displacement. Therefore, the problem of selecting the capacitance of the start capacitors for connection to the excitation winding requires the calculation of these parameters with high reliability, which can be realized only with the use of advanced mathematical models of the SSM, which ensure the high reliability of the results of the mathematical experiment, regardless of the type of motor, its dimensions and parameters.

The goal of the work is the development of a mathematical model that makes it possible to detect and investigate resonance modes during the start-up of SSM with capacitors in the excitation winding circuit.

Algorithm of the problem solution. Let us consider the SSM which stator winding is powered by a threephase network, a starting winding and an excitation winding are placed on the rotor, which at the time of an asynchronous start is shortened to capacitors. The processes are considered in the coordinate axes $d, q$, and the actual winding of the rotor is equivalented by two circuits according using the generally accepted technique. As a result, the electric circuit of the SSM has three contours $(d, f, D)$ along the longitudinal axis and two $(q$, $Q)$ along the transverse one, between which there are interinductive connections due to the saturation of the magnetic core.

The electromagnetic processes in the SSM in the case of shortening of the single-phase excitation winding on capacitors of capacitance $C$ are described by a nonlinear system of differential equations (DE) of the electromagnetic equilibrium of the circuits, which describes the asynchronous mode in the axes $d, q$

$$
\begin{aligned}
& \frac{d \psi_{q}}{d t}=-\omega_{0}(1-s) \psi_{d}-r i_{q}+u_{q} \\
& \frac{d \psi_{D}}{d t}=-r_{D} i_{D} \\
& \frac{d \psi_{Q}}{d t}=-r_{Q} i_{Q} \\
& \frac{d \psi_{f}}{d t}=-r_{f} i_{f}+u_{k} \\
& \frac{d u_{k}}{d t}=\frac{i_{f}}{C}
\end{aligned}
$$

there by the indexes $D$ and $Q$ values concerning equivalent circuits of the starting winding are indicated; $\psi_{d}, \psi_{q}, \psi_{D}, \psi_{Q}, \psi_{f}, i_{d}, i_{q} i_{D}, i_{Q}, i_{f}$ are the flux linkages and currents of the equivalent circuits; $s=\left(\omega_{0}-\omega\right) / \omega_{0}$; $\omega_{0}, \omega$ are the voltage of the feeding voltage of the stator winding and the angular frequency $\left(\mathrm{s}^{-1}\right)$ of the rotor rotation; $u_{d}=U_{m} \sin \theta, u_{q}=U_{m} \cos \theta, \theta$ is the angle of rotor runoff, $U_{m}$ is the amplitude value of the stator phase voltage, $u_{k}$ is the voltage on the capacitor in the excitation winding circuit.

As a result of the periodic change of the angle $\theta$ in the asynchronous mode of the SSM with the sliding of the rotor $s=s_{0}$ flux linkages, currents, voltage on the capacitors of the excitation winding vary according to the periodic law with the period

$$
T_{a}=2 \pi /\left(s \omega_{0}\right)
$$

Thus, the problem of calculating the stationary mode with constant sliding is to determine these periodic dependencies. As is well known [3, 8], it can be solved with a minimum computational volume by solving a boundary value problem with periodic boundary conditions. 
In order to reduce the description of the calculation algorithm for the periodic dependencies of the coordinates of the regime on the period $T_{a}$, we write the system of DE (1) by one vector equation

$$
\frac{d \vec{y}}{d x}=\vec{z}(\vec{x}, \vec{y}, \vec{u}),
$$

where the corresponding vectors have the following content:

$$
\begin{gathered}
\vec{y}=\left|\begin{array}{l}
\psi_{d} \\
\psi_{q} \\
\psi_{D} \\
\psi_{Q} \\
\psi_{f} \\
u_{k}
\end{array}\right| ; \vec{x}=\left|\begin{array}{c}
i_{d} \\
i_{q} \\
i_{D} \\
i_{Q} \\
i_{f} \\
u_{k}
\end{array}\right| ; \vec{u}=\left|\begin{array}{c}
u_{d} \\
u_{q} \\
0 \\
0 \\
0 \\
0
\end{array}\right| ; \\
\vec{z}=\left|\begin{array}{c}
u_{d}+\omega_{0}(1-s) \psi_{q}-r i_{d} \\
u_{q}-\omega_{0}(1-s) \psi_{d}-r i_{q} \\
-r_{D} i_{D} \\
-r_{Q} i_{Q} \\
u_{k}-r_{f} i_{f} \\
i_{f} \\
/ C
\end{array}\right|
\end{gathered}
$$

Having made the approximation of the coordinates of equation (2), which describes the stable asynchronous mode of SSM, on the mesh of $n+1$ nodes of the period $T_{a}$ by the splines of the third order in accordance with [3] with the step $h=T_{a} / n=2 \pi /\left(s \omega_{0} n\right)$, we obtain an algebraic analogue of DE (2) of the $m=6$ th order in the form of a nonlinear algebraic equation of the $n m$-th order

$$
H \vec{Y}-D \vec{Z}=0
$$

where $\vec{Y}=\left(y_{1}, \ldots, y_{n}\right)^{*} ; \vec{Z}=\left(z_{1}, \ldots, z_{n}\right)^{*} ; H, D$ are the transition matrices from continuous change of coordinates to their discrete (nodal) values whose elements are determined by the approximation of periodic coordinates of the coordinates by cubic splines [3].

The algebraic equation (3) is a discrete analogue of the nonlinear system of DE (2). Its solution is the value of the vector

$$
\begin{gathered}
\vec{X}=\left(x_{1}, \ldots, x_{n}\right)^{*}, \\
\left(\vec{x}=\left(i_{d j}, i_{q j}, i_{D j}, i_{Q j}, i_{f j}, u_{k j}\right)^{*}\right), \quad j=1, \ldots, n .
\end{gathered}
$$

The system (3) includes coordinate values that correspond to fixed values of the time coordinate $t$ in the nodes of the period, the relationships between which at each time point are nonlinear. To solve a nonlinear algebraic system (3), the method of extension by parameter in conjunction with the iterative Newton method is applied. The driving force (perturbation) in equation (3) is the vector $\vec{U}=\left(u_{1}, \ldots, u_{n}\right)^{*}$ of discrete values of the applied voltages, where

$$
\vec{u}_{j}=\left(\sqrt{2} U \sin \theta_{j}, \sqrt{2} U \cos \theta_{j}, 0,0,0,0\right)^{*},
$$

increasing which from zero to a given value, we obtain the values of vectors $\vec{Y}$ and $\vec{X}$ which correspond to the specified value of sliding $s=s_{0}$.

Investigation of the effect of the value of capacitors' capacitance $C$ on the asynchronous mode is carried out by the differential method. For this, system (3) is differentiated by $C$. As a result, we obtain the DE of the argument $C$ of the form

$$
W \frac{\partial \vec{X}}{\partial C}=D \vec{U},
$$

where $W$ is the Jacobi matrix of the system (3).

To obtain the multidimensional static characteristic as the dependence of the nodal values of the coordinates of the mode of operation of the SSM on $C$, the system of DE (4) must be integrated by the numerical method [3, 8]. At each step of the integration the derivative vector $\partial \vec{X} / \partial C$ is determined by solving the equation (4), which makes it possible to reduce it by the numerical method to the Cauchy form. Elements of the blocks of the Jacobi matrix are the differential inductive resistances of the motor's circuits, which are determined by calculating the magnetic circuit of the SSM in accordance with the accepted model [8]. The basis of their calculation is the determination of the magnetic field curve in the air gap of the motor by the methods of the theory of circuits, which enables to determine the flux linkages of the circuits that enter to the vector of discrepancies and depend on the set of currents of all motor's circuits.

Examples of the results obtained by calculations based on the above-described algorithm of periodic processes in the stable asynchronous mode and static characteristics provided that the excitation winding is shortened on the capacitors for the motor СДНЗ-2-19-49-24 ( $P=1600 \mathrm{~kW}$, $\left.U_{l}=600 \mathrm{~V}, I=180 \mathrm{~A} ; I_{z}=230 \mathrm{~A} ; 2 p=24\right)$ are presented in Fig $1, a, b$ and Fig. 2, $a-f$.

From presented in Fig. 1 dependencies of electromagnetic torque and effective stator current value on the capacitor's capacitance in the excitation winding of the SSM at sliding $s=1$ it can be seen that when $C=$ $=50 \mu \mathrm{F}$ the resonant mode occurs, resulting in the torque becomes negative, the current value becomes unacceptably large and the motor start becomes impossible. However, the SSM has satisfactory starting properties at capacitance values of capacitors $C=45 \mu \mathrm{F}$. The multiplicity of the driving electromagnetic torque in relation to the nominal value for such a capacity is $M^{*}=3.48$. Fig. 2 shows the periodic dependences of electromagnetic torque, the voltage on the capacitor and the excitation current at two values of capacitors' capacitance: $C=45 \mu \mathrm{F}$ and $C=50 \mu \mathrm{F}$, which show that in the case of resonance $(C=50 \mu \mathrm{F})$ capacitor voltage and current excitation repeatedly exceed nominal values. In addition, the excitation winding current in the absence of resonance has a sharp third harmonic, which is absent in the resonance mode. 

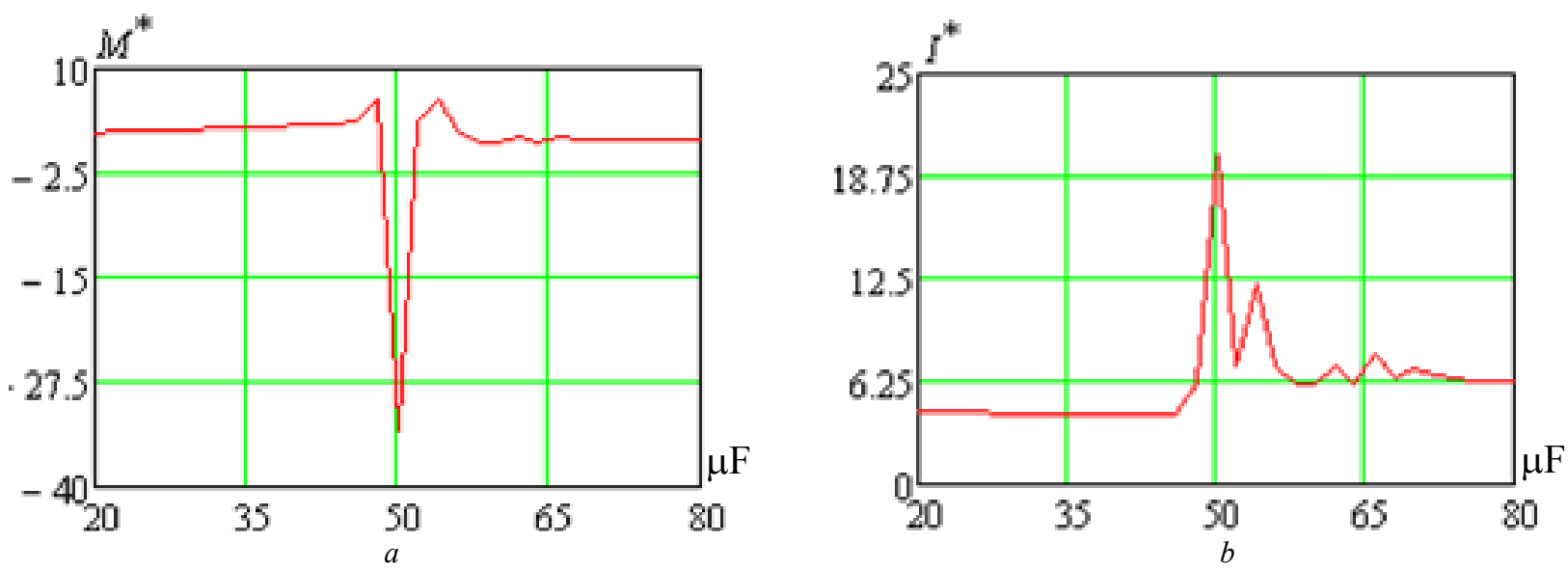

Fig. 1. Dependencies of the driving $(s=1)$ electromagnetic torque $(a)$ tand effective stator current value $(b)$ on the capacitor's capacitance value in the motor's excitation winding: a) $C=50 \mu \mathrm{F}, b) C=45 \mu \mathrm{F}$
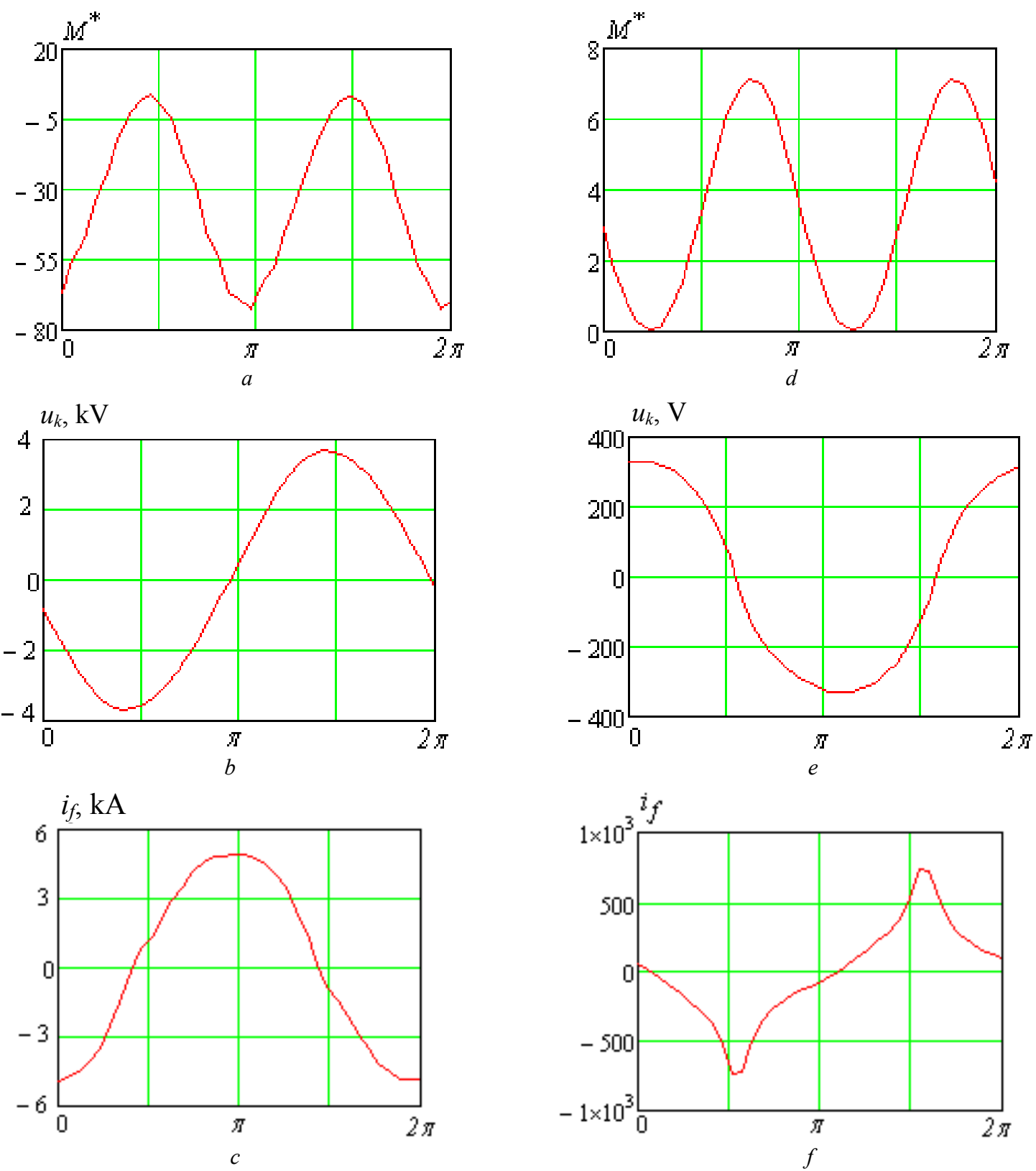

Fig. 2. Periodic dependencies of electromagnetic torque, voltage on the capacitor and excitation current at sliding $s=1$ and two values of the capacitor's capacitance in the excitation winding: $C=50 \mu \mathrm{F}(a-c)$ and $C=45 \mu \mathrm{F}(d-f)$ 


\section{Conclusions.}

1. By connecting capacitors in the excitation winding it is possible to significantly increase the driving electromagnetic torque of the SSM. However, the choice of needed to improve the starting properties of the SSM value of capacitors' capacitances the behavior of the motor in starting modes should be verified, because here may be a resonance in the excitation winding which leads to excessive growth of all circuits currents and the negative value of starting torque, which by the absolute value much exceeds the nominal value and the motor start is impossible.

2. Investigations of the operation of the SSM with capacitors in the excitation winding in asynchronous mode with high adequacy are possible only based on a complete DE system that describes the dynamic mode of operation. This makes it possible to carry out a multivariate analysis of the operation of the electric drive in the starting modes by methods of mathematical modeling.

3. The proposed algorithm and developed on its basis computer code for calculation of steady modes and static asynchronous characteristics of the SSM in the starting mode, allowing you to investigate dynamic processes of the motor start with different capacitors' capacitance values and identify a possibility of resonance phenomena with the aim of preventing them. On the basis of the calculation algorithm a mathematical model of the motor of a high level of adequacy, which considers nonlinearity of electromagnetic connections between circuits of the SSM, distributed along the stator bore the character of magnetic flux in the air gap, is assigned.

\section{REFERENCES}

1. Boroday V.A. Racional'ni parametry i puskovi vlastyvosti synhronnyh dvyguniv z vazhkymy umovamy pusku. Avtoref. diss. kand. tekh. nauk [Rational parameters and starting properties of synchronous motors with heavy start conditions. Abstracts of cand. tech. sci. diss.]. Lviv, 2009. 19 p. (Ukr).

2. Malyar V.S., Maday V.S., Dobushovska I.A. The dependence of a synchronous motor starting torque on the type and value of the resistance in its exitation winding. Electromechanical and energy saving systems, 2012, no.3(19), pp. 99-101. (Ukr).
3. Malyar V.S., Malyar A.V. Mathematical modeling of periodic modes of operation of electrical devices. Electronic Modeling, 2005, vol.27, no.3, pp. 39-53. (Rus).

4. Malyar V.S., Malyar A.V., Dobushovs'ka I.A. Simulation of asynchronous modes of synchronous motors with capacitors in the excitation circuit. Electrical engineering \& electromechanics, 2012, no.5, pp. 31-33. (Ukr). doi: 10.20998/2074-272X.2012.5.06.

5. Malyar V.S., Malyar A.V., Dobushovska I.A. Static characteristics of synchronous motor with capacitors in excitation circuit. Tekhnichna elektrodynamika, 2012, no.1, pp. 57-62. (Ukr).

6. Pivnjak G.G., Kirichenko V.I., Borodaj V.A. About new direction in improvement large synchronous electric motors. Technical electrodynamics. Thematic issue "Problems of modern electrical engineering». 2002, chapter 2, pp. 62-65. (Rus).

7. Pyvnjak G.G., Kyrychenko V.Y., Borodaj V.A., Petrov A.G. Selection and arrangement of external capacitors of synchronous motors with excitation winding of special design. Materialy mezhd. nauchn.-tekhn. konf. "Problemy avtomatizirovannogo elektroprivoda. Teoriia i praktika» [Proceedings of the Int. Sci.Techn. Conf. «Problems of automated electric drive. Theory and practice»]. Kharkov, 2002, pp. 171-173. (Rus).

8. Filc R.V., Ljabuk N.N. Matematicheskoe modelirovanie iavnopoliusnykh sinkhronnykh mashin [Mathematical simulation of explicitly polarized synchronous machines]. Lvov, Svit Publ., 1991. 176 p. (Rus).

Received 25.05.2017

V.S. Malyar ${ }^{1}$, Doctor of Technical Science, Professor,

V.S. Maday ${ }^{1}$, Candidate of Technical Science, Associate Professor,

I.R. Kens ${ }^{2}$, Candidate of Technical Science, Associate

Professor,

${ }^{1}$ Lviv Polytechnic National University,

12, S. Bandera Str., Lviv, 79013, Ukraine,

phone +380322582119 ,

e-mail:mvs@polynet.lviv.ua, volodymyr.s.madai@lpnu.ua

${ }^{2}$ Ukrainian National Forestry University,

103, Gen. Tchuprynky Str., Lviv, 79057, Ukraine,

e-mail: ikens@mail.ru

How to cite this article:

Malyar V.S., Maday V.S., Kens I.R. Resonant processes in starting modes of synchronous motors with capacitors in the excitation windings circuit. Electrical engineering \& electromechanics, 2017, no.4, pp. 21-25. doi: 10.20998/2074272X.2017.4.04. 